\title{
O milho RR2 e o glyphosate: Uma revisão ${ }^{1}$
}

\author{
RR2 corn and glyphosate: A review
}

\begin{abstract}
Alfredo Junior Paiola Albrecht ${ }^{2}$; Leandro Paiola Albrecht ${ }^{2}$; Arthur Arrobas Martins Barroso ${ }^{3}$; Ricardo Victoria Filho ${ }^{4}$
\end{abstract}

Resumo - Os benefícios resultantes da tecnologia Roundup Ready são expressivos e a aceitação desta tecnologia pelos produtores rurais é inegável, dando suporte para o rápido crescimento das áreas de milho RR2. Ao mesmo tempo resultados de pesquisas recentes indicam que o glyphosate aplicado em pós-emergência, em milho RR2, pode, em algumas situações, causar danos ao desenvolvimento das plantas. Porém, persistem muitas especulações e dúvidas que precisam ser melhores elucidadas, no âmbito científico e técnico. Em virtude deste fato, faz-se necessária a busca de informações que permitam diagnosticar as reais consequências do uso do glyphosate nesta cultura e assim, fomentar o posicionamento mais seguro e sustentável desta nova tecnologia, proporcionando aos agricultores benefícios relacionados ao manejo adequado de plantas daninhas nos diversos agroecossistemas.

Palavras-chave: Zea mays, herbicida, culturas transgênicas, plantas daninhas, EPSPs

Abstract - The benefits of the Roundup Ready technology are expressive and the acceptance of this technology by farmers is undeniable, giving support to the rapid growth of RR2 corn. Recent studies indicate, however, that glyphosate applied in post-emergence in RR2 corn can eventually cause damage to plants development. Therefore, there are many speculations and questions that need to be clarified in the scientific and technical context. Thus, it is necessary the search for information allowing to diagnose the real consequences of its use, safer and sustainable positioning of this new technology, providing benefits to farmers related to proper weed management in different agroecosystems.

Keywords: Zea mays, herbicide; transgenic crops, weeds, EPSPs

\section{Introdução}

É de suma importância aumentar cada vez mais a produção e a distribuição de gêneros alimentícios para alimentar uma população mundial que não para de crescer. Ao mesmo tempo, devemos reduzir os impactos ambientais e buscar a sustentabilidade dentro dos agroecossistemas, sendo necessária a utilização responsável e adequada das descobertas científicas e das novas tecnologias disponíveis, como as plantas transgênicas.

A cultura do milho (Zea mays L.), em função de seu potencial produtivo, composição química e valor nutritivo, constitui-se em um dos mais importantes cereais cultivados e consumidos no planeta (Fancelli e Dourado Neto, 2000), juntamente com o arroz e o trigo. Quando relacionamos a cultura do milho às tecnologias transgênicas disponíveis no Brasil,

\footnotetext{
${ }^{1}$ Recebido para publicação em 21/08/2014 e aceito em 15/03/2015.

${ }^{2}$ Professor - UFPR. Palotina, Paraná, Brasil. Email: ajpalbrecht@ yahoo.com.br

${ }^{3}$ Acadêmico de Doutorado - UNESP. Jaboticabal, São Paulo, Brasil.

${ }^{4}$ Professor - ESALQ/USP. Piracicaba, São Paulo, Brasil.
} 
temos os eventos que conferem a resistência a insetos, e mais recentemente passamos a ter grandes áreas cultivadas com milho contendo a tecnologia RR2 (Roundup Ready 2), que se refere ao milho tolerante ao herbicida glyphosate (CIB, 2012). Hoje a maioria do milho transgênico, comercializado no Brasil apresenta os dois eventos, ou seja, a tolerância ao glyphosate e resistência a insetos (CIB, 2013a).

O milho RR2 surgiu devido a problemas que foram identificados com o milho tolerante a glyphosate de primeira geração (milho GA21, lançado em 1980). A enzima (EPSPs) insensível ao glyphosate (Spencer et al., 2000), inserida no milho através de biobalística, possuía um gene promotor originado de plantas de arroz (Os.Act1) e semelhante 99,3\% com a EPSPs selvagem isolada (Cajacob et al., 2007). Porém a expressão da EPSPs nestas plantas era reduzida, principalmente em tecidos novos e reprodutivos, como flores.

Com isso, a aplicação de glyphosate mostrava-se prejudicial em alguns casos, como por exemplo, em plantas de algodão, onde não se recomendava a aplicação do herbicida em plantas mais desenvolvidas (Pline et al., 2002). A aplicação nestas plantas causava queda de capulhos e perdas na produtividade (Jones e Snipes, 1999).

A segunda geração do milho RR possui uma enzima (EPSPs) diferente da primeira. O milho NK603 foi desenvolvido com promotores virais e elementos regulatórios que elevam a expressão da tolerância ao glyphosate na planta, principalmente nos tecidos anteriormente vulneráveis (Cajacob et al., 2007). A homologia desta enzima com a EPSPs selvagem é de 99,7\% segundo os autores (homologia com a EPSPs da bactéria $A$. tumefaciens). Esta mudança sanou o problema existente com as fitointoxicações, e também possibilitou à Monsanto renovar suas patentes e disponibilizar no mercado um material com maior aceitabilidade por parte dos produtores. Destaca-se que no Brasil os primeiros híbridos de milho comerciais tolerantes ao glyphosate, já apresentavam a segunda geração dessa tecnologia RR (NK603 Roundup Ready 2) (CIB, 2013a).

Atualmente a tecnologia Roundup Ready é muito conhecida no Brasil e no Mundo, sendo relacionada inicialmente à soja, e mais recentemente ao milho e a outras culturas. Este fato pode ser atribuído aos expressivos benefícios advindos desta tecnologia, resultando na rápida e grande aceitabilidade por parte dos agricultores. São exemplos destes benefícios a alta eficácia de controle de plantas daninhas pelo uso do glyphosate; a economia na compra de herbicidas (no ano de 1995, eram utilizados 11 herbicidas diferentes na cultura da soja, hoje na maioria das vezes, é utilizado apenas o glyphosate); além dos benefícios ambientais, como a quantidade reduzida de químicos aplicados no solo (Green et al., 2012). Vale ressaltar que essa economia na redução de produtos, mostrou-se nos dias atuais não ser tão benéfica quanto parecia, principalmente devido a seleção de populações resistentes de plantas daninhas.

Devido à grande importância do milho RR2 no cenário nacional e mundial e utilizando como exemplo a cultura da soja tolerante ao glyphosate, que já foi mais intensamente pesquisada a respeito do efeito deste produto, destaca-se que alguns resultados na literatura vigente demonstram que a aplicação de glyphosate pode apresentar efeitos indesejáveis ao milho RR2, porém esses são polêmicos. Este e outros pontos relacionados ao tema serão comentados na sequência, com o objetivo de expor a situação atual da tecnologia e a utilização deste importante herbicida.

\section{O herbicida glyphosate, a tecnologia RR e a cultura do milho}

O glyphosate foi criado em 1950, e depois de passar por várias empresas chegou a Monsanto. Só em 1971, em meio a um programa específico para desenvolver um herbicida sistêmico para controle de plantas perenes é que a função herbicida do glyphosate foi explorada. 
A partir disto, em 1974 o produto denominado Roundup ${ }^{\circledR}$ foi lançado comercialmente, se espalhando rapidamente pelo mundo (Halter, 2009).

Com relação às características deste herbicida, destaca-se que o glyphosate é utilizado em aplicação em pós-emergência, pertence ao grupo químico das glicinas substituídas, é classificado como não seletivo (seletivo somente para culturas geneticamente modificadas - RR). Apresenta amplo espectro de ação, controlando plantas daninhas anuais e perenes, tanto de folhas largas como estreitas. Sua ação é sistêmica, sendo absorvido pelas folhas e tecidos verdes, e redistribuído preferencialmente pelo floema, para os tecidos meristemáticos da planta. Age inibindo a atividade da enzima 5-enolpiruvilshiquimato-3fosfato sintase (EPSPs), que é catalisadora de reações de síntese dos aminoácidos aromáticos fenilalanina, tirosina e triptofano (Galli e Montezuma, 2005; Victoria Filho, 2008). Como resultado, as proteínas, vitaminas, metabolitos secundários $\mathrm{e}$ fotossíntese da planta são alterados, levando essa à morte (Duke et al., 2003).

Produtos que contém o glyphosate em sua formulação são registrados em mais de 130 países, com mais de 150 marcas comercializadas. Seu controle é eficaz para mais de 300 espécies de plantas daninhas, e é utilizado com registro em mais de 100 culturas (Velini et al., 2009; Monsanto, 2012).

A grande eficiência do glyphosate no controle de plantas daninhas, associado à redução significativa de preço desta molécula (ela já estava disponível há vários anos para uso na agricultura, entretanto devido aos elevados preços, sua utilização era limitada), apoiaram a implantação e sucesso do sistema de plantio direto no Brasil. Depois da consolidação do uso deste herbicida, o plantio direto teve expressivo avanço, com crescente expansão no passar dos anos, e outra revolução na agricultura brasileira e mundial vem sendo proporcionada por esta molécula, relacionada à expansão das culturas RR (Galli, 2009).

Hoje a sociedade é testemunha de que as plantas transgênicas apoiaram o surgimento e desenvolvimento de produtos e serviços com grande impacto na vida do agricultor e dos consumidores, em praticamente todo o mundo, devido a diversos benefícios por elas proporcionados (Borém e Santos, 2008). Antes do surgimento e expansão das culturas transgênicas tolerantes a herbicidas, como a Roundup Ready (RR), a maior dificuldade no controle de plantas daninhas que competiam com a cultura comercial, estava diretamente relacionada à dificuldade de um único produto realizar o controle eficaz de todas as infestantes, e ao mesmo tempo ser seletivo à cultura de interesse (Albrecht et al., 2013a).

No caso da cultura do milho, antes da utilização da tecnologia RR, as perdas ocasionadas em função da interferência imposta pelas plantas daninhas eram da ordem de $13 \%$, sendo que em casos onde não tinha sido utilizado nenhum método de controle esta redução poderia chegar a $85 \%$ (EMBRAPA, 2012). Assim, uma das primeiras características transgênicas a serem inseridas com êxito, em culturas comerciais, foi a tolerância ao glyphosate.

Esta tecnologia proporcionou aos agricultores expressivos benefícios e facilidades, estando baseada no herbicida glyphosate, que representa em torno de 12 a $14 \%$ do mercado mundial de defensivos agrícolas, e tem participação de aproximadamente $40 \%$ no mercado dos herbicidas, com uma produção anual do ácido de glyphosate em torno de um bilhão de quilos, apresentando uma taxa média de crescimento no mercado mundial próxima a $15 \%$ por ano (Velini et al., 2009; Monsanto, 2011).

Tratando especificamente da cultura do milho, esta se destaca por sua fonte energética ser considerada por muitos a base da alimentação humana e animal. Atualmente seu processamento dá origem a rações animais, é 
utilizado em indústrias alimentícias, na fabricação de bioplásticos, corantes, espessantes e biocombustíveis, de forma a constituir em uma commodity altamente expressiva. No Brasil, pensando-se no cenário atual de produção de grãos, o milho só não supera a cultura da soja, e segundo a Conab (2014), na safra 2013/2014 a área total de milho (primeira e segunda safra) foi de cerca de 15 milhões de hectares, e a produtividade média de $4.970 \mathrm{~kg} \cdot \mathrm{ha}^{-1}$.

Analisando a importância significativa desta cultura e da tecnologia RR2, salienta-se que na safra (2013/2014), considerando-se a área de milho total (primeira e segunda safra), a adoção de biotecnologia para o cereal totalizou $81,5 \%$ da área total, em que, $41 \%$ apresentavam tolerância a um ou mais herbicidas, sendo esta tolerância a herbicida associada em $90 \%$ dos casos a eventos diversos que conferem resistência a insetos (Céleres, 2013). Nas próximas safras o percentual da área cultivada com milho RR2 irá crescer significativamente, devido a maior oferta de híbridos contendo esta tecnologia e também a maior quantidade de semente a ser disponibilizada no mercado apresentando tolerância ao glyphosate.

De acordo com registros atualizados, o milho é no Brasil a cultura com maior número de eventos transgênicos aprovados pela CTNBio, com 23 eventos (sejam estes isolados ou combinados). Destes, 17 apresentam algum tipo de tolerância a herbicidas (glyphosate e/ou glufosinato de amônio e um caso com tolerância ao 2,4-D) e 13 deles contêm a tecnologia RR2. A maioria dos eventos combina mais de uma tecnologia, por exemplo, sete eventos apresentam tolerância aos herbicidas glyphosate e glufosinato de amônio (LL) somadas a diferentes eventos que proporcionam resistência a insetos. Inclusive os últimos cinco eventos transgênicos, em plantas, aprovados pela CTNBio foram na cultura do milho (CIB, 2015).

A soja é hoje a cultura RR mais difundida no Mundo, e no Brasil representou na safra 2013/2014, 92\% da área semeada (CIB, 2013b). A exemplo da soja, o milho RR2 apresenta grande potencial de aceitação pelos produtores brasileiros nos próximos anos. Essa tecnologia já é amplamente utilizada em países como Estados Unidos, Canadá, Argentina, África do Sul, Filipinas, Colômbia, Uruguai, Paraguai e importada para consumo pela União Européia, Japão, México, Austrália, Nova Zelândia, Rússia, Taiwan, Coréia do Sul, China, Malásia e Singapura (Monsanto, 2013). O primeiro evento com esta tecnologia foi aprovado no Brasil em 2008, pela CTNBio (CIB, 2013a), mas comercialmente áreas significativas foram cultivadas somente em 2011, sendo com isso bem recente a sua utilização pelos produtores.

Outros eventos transgênicos relacionados à tolerância a herbicidas estão sendo desenvolvidos para a cultura do milho, e estarão disponíveis em breve. Entre eles destaca-se o sistema Enlist, que trará a tolerância ao glyphosate, e a um produto baseado no 2,4-D (Dow, 2011). Ainda estão sendo desenvolvidos alguns eventos que combinarão tolerâncias a mais de três diferentes mecanismos de ação, em uma única planta, como é o caso dos eventos glyphosate + glufosinato + ACCase e glyphosate + 2,4-D + glufosinato + ACCase (Albrecht et al., 2013a).

\section{Glyphosate em milho RR2}

Partindo-se do pressuposto que o glyphosate pode apresentar alguns efeitos indesejáveis mesmo em culturas RR, para as quais é considerado seletivo, destaca-se que qualquer estresse acarretará efeito negativo sobre o crescimento e desenvolvimento normal das espécies vegetais (Taiz e Zeiger, 2013). Quando levamos em consideração o fato da utilização recente do milho RR2 pelos produtores brasileiros, recomenda-se cautela, pois faltam informações concretas sobre os possíveis efeitos que o glyphosate pode causar a esta cultura sob as condições edafoclimáticas brasileiras.

Neste sentido, resultados de pesquisas abordando o efeito do glyphosate sobre o 
desenvolvimento da soja tolerante ao glyphosate apresentam maior número de estudos sobre o assunto, em relação ao milho RR2. Estas pesquisas demonstram que este herbicida pode influenciar o balanço nutricional, gerar efeitos fitotóxicos, afetar a eficiência no uso da água, a fotossíntese, a rizosfera, o acúmulo de biomassa, a síntese de aminoácidos e compostos secundários, e também afetar a qualidade das sementes e grãos produzidos (Kremer et al., 2005; Neumann et al., 2006; Zablotowicz e Reddy, 2007; Zobiole et al., 2010a,b,c; Albrecht e Ávila, 2010; Albrecht et al., 2011a,b; Albrecht et al., 2012a,b; Alonso et al., 2013). Assim, trabalhos como estes denotam a possibilidade de comprometimento do desempenho agronômico de culturas RR, como o Milho RR2, sob aplicação de glyphosate em pós-emergência, mesmo a cultura sendo tolerante a este produto.

Entre os trabalhos realizados abordando o milho RR2 no Brasil, em alguns casos verificou-se efeitos indesejáveis na cultura após a aplicação de diferentes formulações de glyphosate, como alterações nos teores de nutrientes em folhas (Costa et al., 2012), efeitos negativos sobre a taxa fotossintética e condutância estomática (Guerra et al., 2012), danos prejudiciais ao desenvolvimento das raízes das plantas (Oliveira Neto et al., 2012), e até redução na produção de grãos (Correia et al., 2012).

Devido à escassez de informações concretas e muitas dúvidas que persistem e precisam ser melhores elucidadas no âmbito científico e técnico, relacionadas a possíveis efeitos do glyphosate sob o desenvolvimento da cultura de milho RR2, mais estudos devem ser realizados nesta linha de pesquisa. Neste sentido, resultados parciais com milho RR2 indicaram uma tendência de diminuição da clorofila A e B nas folhas (caracterizando visualmente a clorose), com o aumento das doses de glyphosate (Albrecht et al., 2012c).

Dos estudos existentes no exterior, um deles relata diferenças em características entre variedades não tolerantes e tolerantes ao glyphosate no milho RR2 (Nolte e Young, 2002), e dois relatam a inexistência de diferenças (Beckie et al., 2006; Thelen e Penner, 2007). Segundo Nolte e Young (2002), esta diferença (o híbrido de milho tolerante ao glyphosate produziu menos do que os demais testados) ocorreu devido às condições climáticas do ano em estudo. Nos demais estudos, não foram encontradas diferenças no crescimento, desenvolvimento e produtividade da cultura. As possíveis interações entre a aplicação de glyphosate e a presença de micotoxinas, não ocorreram de forma expressiva.

Segundo Thomas et al. (2004), a aplicação de glyphosate em milho RR2, em estádios superiores ao estádio V6, pode afetar a reprodução individual de plantas, pois afeta a quantidade e a qualidade de pólen produzido, assim como está relacionada a alterações no tamanho dos vacúolos. Este efeito, porém, não foi suficiente neste estudo para prejudicar a polinização e consequentemente a produtividade da cultura.

O estudo dos efeitos pleiotrópicos dos genes responsáveis pela tolerância a glyphosate, ficarão cada vez mais difíceis de serem realizados. A estaquia com outros genes, como a resistência a insetos, torna cada vez mais difícil a associação entre o efeito e a causa, sendo difícil isolar o efeito da tolerância a herbicidas.

Outros dados preliminares de alguns experimentos conduzidos em parceria entre as instituições USP/ESALQ e UFPR, realizados na segunda safra (safrinha) de 2013 indicaram impactos sobre o desenvolvimento da cultura, como pequenas alterações nos teores de clorofilas em algumas doses e formulações, segundo dados apresentados por Krenchinski et al. (2013a). Também foi observado decréscimo linear da altura das plantas, 21 dias após a aplicação, em função do aumento das doses de glyphosate (Krenchinski et al., 2013b). Verificou-se ainda interferências na produtividade e leve redução na massa de cem 
grãos, em função da aplicação de altas doses de glyphosate (Albrecht et al., 2013b).

Percebendo a necessidade de maiores explicações sobre este assunto, outros projetos de grandes proporções vêm sendo conduzidos no momento, como, por exemplo, o projeto realizado por pesquisadores norte americanos, que pretende verificar a possibilidade da ocorrência de efeitos deletérios do glyphosate sobre culturas RR, avaliando o conteúdo mineral do milho RR2 sob efeito do glyphosate (USDA, 2013).

Algumas informações técnicas indicam que herbicidas que eram utilizados normalmente em milho sem a tecnologia RR2, poderiam resultar em maiores danos à cultura do que o glyphosate em milho RR2, devido à melhor seletividade neste sistema, além deste proporcionar maior flexibilidade e facilidade no controle das plantas daninhas. Neste contexto, existem pesquisas que mostram que o glyphosate não traz danos significativos ao milho RR2, quando aplicado dentro das doses recomendadas. Mas mesmo levando em consideração que altas doses não apresentam recomendação oficial, observa-se facilmente situações práticas que eventualmente utilizam doses elevadas de glyphosate, na maioria das vezes o produtor não está ciente dos possíveis efeitos nocivos deste incremento na dose.

Como o glyphosate apresenta um custo e uma toxicidade relativamente baixa, quando comparado a outros herbicidas, e com a problemática de plantas daninhas resistentes a este mecanismo de ação (EPSPs), ou mesmo de infestantes tolerantes ao glyphosate, ou altas infestações, ou ainda plantas daninhas fora do ponto adequado de controle, ou perenizadas, esta aplicação de altas doses acaba sendo realizada de forma errônea.

Quando falamos em resistência de plantas daninhas ao glyphosate é interessante notar que nos últimos anos as culturas RR promoveram o uso repetitivo e em grande escala deste princípio ativo. Assim surgiram e continuam surgindo vários registros de plantas daninhas resistentes a este mecanismo de ação. O aparecimento de biótipos de plantas daninhas resistentes ao glyphosate está diretamente relacionado ao desenvolvimento e expansão das culturas RR, pois com o uso continuado deste herbicida ocorreu uma maior pressão de seleção destes biótipos (Heap, 2013).

Hoje temos registradas 32 espécies de plantas daninhas resistentes ao glyphosate, em várias regiões agrícolas do mundo. Os Estados Unidos, que foi o país precursor das culturas $\mathrm{RR}$, apresenta 14 espécies de plantas daninhas resistentes ao glyphosate. Austrália e Argentina que aderiram a tecnologia RR anteriormente ao Brasil apresentam respectivamente dez e sete espécies resistentes. O Brasil apresenta seis espécies resistentes, na Espanha constam cinco registros, e a África do Sul, apresenta três espécies resistentes (Heap, 2015).

Com a expansão do milho RR2 também passaram a ocorrer problemas com as associações do glyphosate com inseticidas, fertilizantes foliares e principalmente outros herbicidas, pois dependendo da combinação pode-se potencializar a fitointoxicação na cultura, e ainda comprometer a eficiência de controle das plantas daninhas. Este fato denota mais uma vez a necessidade contínua de pesquisas nesta área. Vale ressaltar que estresses ambientais podem alterar a expressão da EPSPs nas plantas, tornando-as mais ou menos suscetíveis aos herbicidas.

Infere-se que, a partir da literatura disponível dentro desta linha de pesquisa, em algumas situações pode-se assumir consequências negativas do uso do glyphosate, no milho RR2, sobre seu balanço nutricional, fatores bioquímicos e fisiológicos, consequentemente afetando o desenvolvimento e os componentes de produção da cultura. $\mathrm{O}$ efeito desta aplicação em características bioquímicas das plantas, assim como nutricionais dos grãos, devem ser analisados para obter melhores conclusões sobre estes efeitos. 
A oportunidade de estudos na área é grande. Novos mecanismos de tolerância ao glyphosate estão sendo estudados e os genes caracterizados, de maneira a serem utilizados futuramente em culturas de interesse agronômico. Por exemplo, as enzimas que inativam o glyphosate (GDC-1 e GDC-2), homólogas às descarboxilases (Hammer et al., 2007). Outro exemplo a ser citado, é a descoberta de enzimas com baixa afinidade ao herbicida e elevada afinidade com o substrato, no caso, o fosfoenolpiruvato (PEP). Segundo Vande Berg et al. (2008), existem enzimas como a aroA1398, que apresentam até 800 vezes mais resistência ao herbicida do que as existentes.

Ainda, o estudo e caracterização da resistência de plantas daninhas, abre cada vez mais o leque para a seleção destes genes. Atualmente, o estudo de genes responsáveis pelos mecanismos de resistência não-alvo vem chamando a atenção das empresas, para sua utilização em culturas, pois geralmente estes genes estão associados a impactos positivos no desenvolvimento de plantas, por exemplo, em plantas de Lolium rigidum, foram observados genes nucleares que elevam a resistência ao glyphosate mais do que 100 vezes (Simarmata et al., 2005).

\section{Considerações Finais}

Com base na literatura apresentada e discutida, entende-se que os efeitos da aplicação de glyphosate sobre o milho RR2, devem ser investigados continuamente e intensamente, pois dentro desta linha de estudo faltam informações mais completas, como por exemplo, as disponíveis para a soja tolerante ao glyphosate.

Estas respostas serão encontradas com a continuidade do processo de geração de conhecimento, proveniente da pesquisa dirigida, avaliando o real impacto da aplicação de diferentes formulações, doses e manejos de glyphosate, na cultura do milho RR2, em distintas condições de campo, dentro do território brasileiro.
Com a obtenção e divulgação de informações neste sentido, espera-se fomentar o posicionamento mais seguro desta tecnologia, propiciando a diminuição de alguns possíveis efeitos deletérios do glyphosate sobre a cultura do milho RR2 e seu sistema de produção. Favorecendo assim, o uso sustentável desta ferramenta que apresenta grande potencial de utilização pelos produtores brasileiros, proporcionando benefícios relacionados ao manejo adequado de plantas daninhas nos diversos agroecossistemas.

\section{Referências}

ALBRECHT, L.P.; ÁVILA, M.R. Manejo de glyphosate em soja RR e a qualidade das sementes. Informativo Abrates, v.20, n.2, p.45-54, 2010.

ALBRECHT, L.P. et al. Qualidade fisiológica das sementes de soja RR em resposta ao uso de diferentes tratamentos contendo glyphosate em aplicação sequencial. Bioscience Journal, v.27, n.2, p.211-220, 2011a.

ALBRECHT, L.P. et al. Desempenho da soja Roundup Ready sob aplicação de glyphosate em diferentes estádios. Planta Daninha, v.29, n.3, p.558-590, $2011 \mathrm{~b}$.

ALBRECHT, L.P. et al. Glyphosate e associações em pós-emergência no desempenho agronômico e na qualidade das sementes de soja RR. Planta Daninha, v.30, n.1, p.139-146, 2012a.

ALBRECHT, L.P. et al. RR Soybean seed quality after application of glyphosate in different stages of development. Revista Brasileira de Sementes, v.34, n.3, p.373-381, 2012b.

ALBRECHT, A.J.P. et al. Efeito da aplicação de glyphosate sob o desenvolvimento da cultura de milho RR. In: CONGRESSO NACIONAL DE MILHO E SORGO, 29, 2012, Águas de Lindóia. Resumos...Campinas: IAC/ABMS, 2012c. p. 1132-1137. 
ALBRECHT, L.P.; ALBRECHT, A.J.P.; VICTORIA FILHO, R. Soja RR e o Glyphosate. In: ALBRECHT, L.P.; MISSIO, R.F. Manejo de cultivos transgênicos. Curitiba: UFPR, 2013a. p.25-45.

ALBRECHT, A.J.P. et al. Efeito do glyphosate na produtividade do milho RR2 cultivado na safrinha. In: XII SEMINÁRIO NACIONAL DE MILHO SAFRINHA, 2013, Dourados. Anais...Brasília: Embrapa, 2013b.

ALONSO, D.G. et al. Seletividade de glyphosate isolado ou em misturas para soja RR em aplicações sequenciais. Planta Daninha, v.31, n.1, p.203-212, 2013.

BECKIE, H.J. et al. A decade of herbicideresistant crops in Canada. Canadian Journal of Plant Science, v.86, n.4, p.1243-1264, 2006.

BORÉM, A.; SANTOS, F.R. Variedades resistentes a herbicidas: legislação e liberação. In: CONGRESSO BRASILEIRO DE CIÊNCIA DAS PLANTAS DANINHAS, 26; CONGRESO DE LA ASOCIACIÓN LATINOAMERICANO DE MALEZAS, 28., 2008, Ouro Preto. A ciência das plantas daninhas na sustentabilidade dos sistemas agrícolas: palestras apresentadas. Sete Lagoas: SBCPD; Embrapa Milho e Sorgo, 2008. p.165-178.

CAJACOB, C.A. et al. Genetically modified herbicide resistant crops. In : Modern Crop Protection Compounds, ed. By KRAMER, W. ; SCHIRMER, W. Wiley-vch, Weinheim, Germany, p.283-316, 2007.

CELERES. Informativo biotecnologia. 2013. Disponível http://celeres.com.br/wordpress/wpcontent/uploads/2013/12/IB13021.pdf. Acesso em: 03 de março de 2014.

CIB. Conselho de Informações sobre Biotecnologia: Informações Gerais. 2012. Disponível em: http://cib.org.br. Acesso em: 10 de novembro de 2013.
CIB. Conselho de Informações sobre Biotecnologia: Eventos Aprovados - CTNBio. 2013a. Disponível em: http://cib.org.br/biotecnologia/regulamentacao/ ctnbio/eventos-aprovados. Acesso em: 13 de maio de 2013.

CIB. Conselho de Informações sobre Biotecnologia: Adoção de soja transgênica chega a 92\% das lavouras, diz estudo da Céleres. 2013b. Disponível em: http://cib.org.br/em-dia-com-a-ciencia/adocaode-soja-trangenica-chega-a-92-das-lavourasdiz-estudo-da-celeres Acesso em: 8 ago. 2013.

CIB. Conselho de Informações sobre Biotecnologia: Eventos Aprovados - CTNBio. $2015 . \quad$ Disponível em: http://cib.org.br/biotecnologia/regulamentacao/ ctnbio/eventos-aprovados Acesso em: 19 de junho de 2015.

CONAB. Acompanhamento da safra brasileira: Grãos: Safra 2013/2014, sexto levantamento, março de 2014. Brasília, 2014, 83 p.

CORREIA, N.M.; SANTOS, E.A.; BALIEIRO, G. Teores foliares de macro e micronutrientes e produtividade de milho tolerante ao herbicida glyphosate. In: CONGRESSO BRASILEIRO DA CIÊNCIA DAS PLANTAS DANINHAS, 28. 2012, Campo Grande. Anais...São Paulo: Sociedade Brasileira da Ciência das Plantas Daninhas, 2012. p.1-5.

COSTA, S.S.D. et al. Análise nutricional do milho RR submetido a diferentes formulações de glyphosate e a competição por plantas daninhas tolerantes. In: CONGRESSO BRASILEIRO DA CIÊNCIA DAS PLANTAS DANINHAS, 28. 2012, Campo Grande. Anais...São Paulo: Sociedade Brasileira da Ciência das Plantas Daninhas, 2012. p.341-345.

DOW. Novo Sistema de Controle de Plantas Daninhas. 2011. Disponível em: http://www.dowagro.com/br/recursos/2011/201 10302.htm. Acesso em: 08 de maio de 2013. 
DUKE, S.O. et al. Isoflavone, glyphosate, and aminomethylphosphonic acid levels in seeds of glyphosate-treated,

glyphosate-resistant soybean. Journal of Agricultural and Food Chemistry, v.51, n.1, p.340-344, 2003.

\section{EMBRAPA. Sistema de Produção: Cultivo do Milho. 2012. Disponível em:} http://www.cnpms.embrapa.br/publicacoes/mil ho_8_ed/index.htm Acesso em: 13 de maio de 2013.

FANCELLI, A.L.; DOURADO NETO, D. Ecofisiologia e fenologia. In: FANCELLI, A. L.; DOURADO NETO, D. Produção de milho. Guaíba: Agropecuária, 2000. p.21-54.

GALLI, A.J.B.; MONTEZUMA, M.C. Glifosato: alguns aspectos da utilização do herbicida glifosato na agricultura. [S.1.]: ACADCOM, 2005. 66p.

GALLI, A.J.B. A molécula glyphosate e a agricultura brasileira. In: VELINI, E.D.; MESCHEDE, D.K.; CARBONARI, C.A.; TRINDADE, M.L.B. Glyphosate. Botucatu: FEPAF, 2009. p.17-19.

GREEN, J.M. The benefits of herbicideresistant crops. Pest Management Science, v.68, n.10, p.1323-1331, 2012.

GUERRA, N. et al. Atividade fotossintética do milho RR após a aplicação de glyphosate isolado ou em mistura com atrazine. In: CONGRESSO BRASILEIRO DA CIÊNCIA DAS PLANTAS DANINHAS, 28. 2012, Campo Grande. Anais...São Paulo: Sociedade Brasileira da Ciência das Plantas Daninhas, 2012. P.153-157.

HALTER, S. História do herbicida agrícola glyphosate. In: VELINI, E.D.; MESCHEDE, D.K.; CARBONARI, C.A.; TRINDADE, M.L.B. Glyphosate. Botucatu: FEPAF, 2009. p. 11-16.

HAMMER, P.E. et al. Inventors - Arthenix Corporation, Assignee. 10/05/2007. Methods to confer herbicide resistance. U.S. patent application. 20070107078 A1, 1-53.
HEAP, I. International survey of herbicide resistant weeds. 2013. Disponível em: http://www.weedscience.org/In.asp. Acesso em: 10 de outubro de 2013.

HEAP, I. International survey of herbicide resistant weeds. 2015. Disponível em: http://www.weedscience.org/Summary/MOA.a spx?MOAID=12. Acesso em: 18 de junho 2015.

JONES, M.A.; SNIPES, C.E. Tolerance of transgenic cotton to topical applications of glyphosate. The Journal of Cotton Science, v.3, n.1, p.19-26, 1999.

KREMER, R.J.; MEANS, N.E.; KIM, S. Glyphosate affects soybean an root exudation and rhizosphere micro-organims. International Journal of Environmental and Analytical Chemistry, v.85, n.15, p.1165-1174, 2005.

KRENCHINSKI, F.H. et al. Avaliação dos índices de clorofila em milho RR2 cultivado na safrinha, submetido à aplicações de glyphosate. In: SEMINÁRIO NACIONAL DE MILHO SAFRINHA, 12. 2013, Dourados. Anais... Brasília: Embrapa, 2013a.

KRENCHINSKI, F.H. et al. Efeito do glyphosate na altura do milho RR2 cultivado na safrinha. In: SEMINÁRIO NACIONAL DE MILHO SAFRINHA, 12. 2013, Dourados. Anais... Brasília: Embrapa, 2013b.

MONSANTO. Monsanto em campo: boletins informativos. 2011. Disponível em: http://www.monsanto.com.br/monsanto/brasil/ newsletter/geral. Acesso em: 26 março de 2012. MONSANTO. Produtos: herbicidas. 2012. Disponível em: http://www.monsanto.com.br/produtos/herbicid as/herbicidas.asp. Acesso em: 22 de novembro de 2012.

MONSANTO. Produtos - Milho Roundup Ready. 2013. Disponível em: http://www.monsanto.com.br/sustentabilidade/ produtos/milho_roundup_ready_2/milho_roun 
dup_ready_2.asp. Acessado em: 08 de maio de 2013.

NEUMANN, G. et al. Relevance of glyphosate transfer to non-target via the rhizosphere. Journal of Plant Disease and Protection, v.20, n.esp., p.963-969, 2006.

NOLTE S.A.; YOUNG B.G. Efficacy and economic return on investment for conventional and herbicide-resistant corn (Zea mays). Weed Technology, v.16, n.2, p.371-378, 2002.

OLIVEIRA NETO, A.M. et al. Influência do glyphosate isolado ou em mistura com atrazine sobre o desenvolvimento inicial do milho RR. In: CONGRESSO BRASILEIRO DA CIÊNCIA DAS PLANTAS DANINHAS, 28. 2012, Campo Grande. Anais... São Paulo: Sociedade Brasileira da Ciência das Plantas Daninhas, 2012. p. 161-165.

PLINE, W.A. et al. Reproductive abnormalities in glyphosate-resistant cotton caused by lower CP4-EPSPS levels in the male reproductive tissue. Weed Science, v.50, n.4, p.438-447, 2002.

SIMARMATA, M.; BUGHRARA, S.; PENNER, D. Inheritance of glyphosate resistance in rigid ryegrass (Lolium rigidum) from California. Weed Science, v.53, n.5, p.615-619, 2005.

SPENCER, M.; MUMM, R.; GWYN, J. Inventors - DeKalb Genetics Corporation, assignee. 21/03/2000. Glyphosate resistant maize lines. U.S.patent 6040497.

TAIZ, L.; ZEIGER, E. Fisiologia vegetal. 4. ed. Porto Alegre: Artmed, 2013. 918p.

THELEN, K.D.; PENNER, D. Yield environment affects glyphosate-resistant hybrid response to glyphosate. Crop science, v.47, n.5, p.2098-2107, 2007.

THOMAS, W.E. et al. Glyphosate negatively affects pollen viability but not pollination and seed set in glyphosate resistant corn. Weed Science, v.52, n.4, p.725-734, 2004.
USDA. Research project: determination of the effect of glyphosate on mineral content of glyphosate-resistant crops. 2013. Disponível em:

http://www.ars.usda.gov/research/projects/proj ects.htm?ACCN_NO=422641. Acesso em: 01 de abril de 2014.

VANDE BERG, B.J. et al. Characterization and plant expression of a glyphosate-tolerant enolpyruvylshikimate phosphate synthase. Pest Management Science, v.64, n.4, p.340-345, 2008.

VELINI, E.D. et al. Glyphosate. Botucatu: FEPAF, 2009. 493p.

VICTORIA FILHO, R. Estratégias de manejo de plantas daninhas. In: ZAMBOLIM, L.; ZUPPI, M.; SANTIAGO, T. O que engenheiros agrônomos devem saber para orientar o uso de produtos fitossanitários. 3. ed. São Paulo: ANDEF, 2008. p.397-464.

ZABLOTOWICZ, R.M.; REDDY, K.N. Nitrogenase activity, nitrogen content, and yield responses to glyphosate in glyphosate-resistant soybean. Crop Protection, v.26, n.3, p.370376, 2007.

ZOBIOLE, L.H.S. et al. Effect of glyphosate on symbiotic N2 fixation and nickel concentration in glyphosate-resistant soybeans. Applied Soil Ecology, v.44, n.2, p.176-180, 2010a.

ZOBIOLE, L.H.S. et al. Water use efficiency and photosynthesis of glyphosate-resistant soybean as affected by glyphosate. Pesticide Biochemistry and Physiology, v.97, n.3, p.182-193, $2010 b$.

ZOBIOLE, L.H.S. et al. Glyphosate affects lignin content and amino acid production in glyphosate-resistant soybean. Acta Physiologiae Plantarum, v.32, n.5, p.831-837, 2010c. 